Canadian Studies in Population, Vol. 37.3-4, Fall/Winter, pp. 617-619

\title{
Poverty Reduction An Effective Means of Population Control
}

\author{
Mohammed Sharif \\ London: Ashgate, 2007 \\ ISBN 978-0-7546-4728-7 \\ EUR€ 97.00, 184 pages \\ Reviewed by \\ Neeru Gupta \\ World Health Organization
}

Every first-year demography student learns about the demographic transition theory, a framework used to represent the processes of transformations of societies characterized with high birth and death rates to ones with low birth and death rates, in conjunction with economic development. The theory mainly draws on hypotheses inspired by observation of broad trends having occurred at various times across different regions of the world. It has its proponents given its generalizable approach to explaining global demographic trends, but is notoriously deficient as a model for understanding the causal effects between economic development and fertility outcomes, predicting future demographic trends in a given society, or describing individual cases.

Decades after the first scientific publications on demographic transition, demographers - both established researchers and the upcoming generation - continue to study and debate the interrelationships between fertility and economic development, notably in the context of persistent high fertility and extreme poverty in parts of the developing world. Conclusive evidence on a critical catalyst to fertility decline in a country remains elusive.

In the book Poverty Reduction - An Effective Means of Population Control, the author takes a strong stance that "it is poverty that increases fertility, not the other way around." Mohammed Sharif, professor at the University of Rhode Island, argues that this conclusion is reached based on review of the literature on population policy and fertility behaviour of the poor in developing countries, combined with statistical testing of the "irrationality" hypothesis of population policy using data from multiple countries. He starts from the premise that policy makers assume that the poor do not make their decisions rationally. He presents ten chapters using various arguments and empirical analyses to support his contention. He claims his ultimate goal, shaped in part by his personal experiences

CSP 2010, 37.3-4: 617-619 
growing up in rural Bangladesh, is that the findings will be used to inform policy decisions - specifically, policies prioritizing poverty reduction, and not fertility reduction through family planning programmes.

As a resource for new thinking and review of current literature in the fertility-poverty debate, the book comes up short. Many chapters contain disproportionately few (if any) bibliographic references dating since 2000. This year marked the adoption by the United Nations of the Millennium Development Goals (MDGs) compact for combating poverty and its causes and consequences. While the book makes some reference to the MDGs, elsewhere the author contends that "there is no ... specific commitment [by the world community] to address the problem of global poverty[" The author criticizes UNFPA for spending "about US\$20 billion annually on activities directed towards reducing fertility through changing the supposedly irrational behaviour of the poor" - without either substantiating the monetary figure (UNFPA reported its total annual expenditure in 2007 at US\$629 million) or acknowledging the organization's actual mission statement ("supports countries in using population data for policies and programmes to reduce poverty and to ensure that every pregnancy is wanted, every birth is safe, every young person is free of HIV/AIDS, and every girl and woman is treated with dignity and respect.") 1

Throughout the book, the author generally avoids mention of possible arguments in favour of support for family planning programmes, such as the sexual and reproductive health dimension or the human rights perspective. There is no mention at all of the HIV/AIDS epidemic, and the dual role of population programmes in promoting barrier methods for protection from unplanned pregnancy as well as HIV and other sexually transmitted infections. Although the author identifies what the poor lack most are resources, when it comes to the role of public programmes in supporting access to contraceptive resources and a woman's right to choose, silence is not golden. The only reference in the book to promoting women's empowerment regards it among programmatic "drawbacks... [by] creating friction in the family."

With regard to the empirical analysis, the author relies heavily on macro-level data extracted from reports and databases of the United Nations Statistics Division and other international agencies. There is little scrutiny of the quality of these data or the underlying national information systems that feed the international compilations. The analyses themselves are disjointed, sometimes with one chapter presenting a picture using older data and then another using the same approach but with more recent data. Midway through, the book jumps 
into a purely theoretical approach, peppered with series of algebraic formulas. There is no use of micro-level longitudinal or retrospective data, nothing in the models that can be considered to statistically validate a causal claim.

Although the basic premise of the book, that the poor are able to make rational decisions for themselves, may be sound, the methods and arguments to support this claim are selective, inconclusive and even sometimes contradictory. A first-year demography student might find it an interesting complementary read to gather a particular viewpoint into the demographic transition theory and fertility-poverty debate. But it is highly unlikely a decision-maker would use this material to inform policy and programme options.

1. UNFPA Annual Report 2007. New York: United Nations Population Fund, 2007

$<$ http://www.unfpa.org/webdav/site/global/shared/documents/publ ications/2008/ar07_eng.pdf>. 